\title{
Research Paper: An Investigation on the Relationship Between Self-efficacy With Spiritual Adjustment and Life Expectancy in Adult Earthquake Residents in Sarpol-e Zahab City, Iran in 2019
}

\author{
Mazyar Dogohar ${ }^{1}$, Shayesteh Salehi ${ }^{2 *}$, Narges Sadeghi
}

1. Department of Community Health Nursing, Community Health Research Center, Faculty of Nursing and Midwifery, Khorasgan Branch, Islamic Azad University, Isfahan, Iran

2. Community Health Research Center, Faculty of Nursing and Midwifery, Khorasgan Branch, Islamic Azad University, Isfahan, Iran.

\begin{tabular}{l|l}
$\begin{array}{c}\text { Use yourdevice to scan } \\
\text { and read the article online }\end{array}$ \\
ment and Life Expectancy in Adult Earthquake Residents in Sarpol-e Zahab City, Iran in 2019. Health in Emergencies and Disasters \\
Quarterly. 2020; 5(4):215-226. http://dx.doi.org/10.32598/hdq.5.4.337.1
\end{tabular}

\section{(1) (3)}

Article info:

Received: 19 Oct 2019

Accepted: 06 Jun 2020

Available Online: 01 Jul 2020

\section{Keywords:}

Earthquake, Self-efficacy, Spiritual adjustment, Life expectancy

\section{A B S T R ACT}

Background: Earthquakes are among the most natural catastrophic disasters. Adults' response to disasters largely depends on their physical health, mobility, self-efficacy, resource, and income level The purpose of this study was to determine the relationship between self-efficacy with spiritual adjustment and life expectancy in earthquake-stricken adults living in Sarpol-e Zahab City, Iran.

Materials and Methods: The present study is a descriptive-analytical study that was done on 135 earthquake-stricken adults in Sarpol-e Zahab City. The study data were collected using the Scherer general self-efficacy questionnaire, Herth's life expectancy questionnaire, spiritual adjustment, and demographic data in Spring 1998. The obtained data were analyzed by SPSS version 24 and descriptive and inferential statistics.

Results: In this study, 135 adults were enrolled, $65.2 \%$ were men and the rest were women. The Mean \pm SD age of the samples was $41.64 \pm 11.49$ years. The Mean \pm SD values of self-efficacy, spiritual adjustment, and life expectancy were $55.64 \pm 10.29,150.47 \pm 35.17$, and $28.44 \pm 5.75$, respectively. There was a significant and positive correlation between self-efficacy and spiritual adjustment. There was a positive and significant relationship between self-efficacy and life expectancy as well as life expectancy and spiritual adjustment.

Conclusion: The findings of the present study showed a high correlation between selfefficacy, life expectancy, and spiritual adjustment. People with high spiritual well-being and life expectancy are more adaptable to their problems; accordingly, their reinforcement of spiritual well-being and life expectancy increases their adaptability to the situation. Therefore, it is recommended that educational programs be developed to increase the self-efficacy of earthquake-affected individuals and increase their life expectancy and spiritual well-being.

\footnotetext{
* Corresponding Author:

Shayesteh Salehi, PhD.

Address: Community Health Research Center, Faculty of Nursing and Midwifery, Khorasgan Branch, Islamic Azad University, Isfahan, Iran.

E-mail: salehi@nm.mui.ac.ir
} 


\section{Introduction}

uman life is always faced with two kinds $\mathbf{H}$ of natural and human problems. Unlike human issues, man is not responsible for the creation of natural disasters. These events happen from time to time and create heartbreaking catastrophes. In terms of surprise and unpredictability, the earthquake is ranked first among natural disasters [1]. Earthquake is among the most catastrophic disasters and leaves many casualties around the world annually. Iran is also one of the earthquake-prone countries in the world because it is located on one of the seismic belts [2]. Since 2000, major earthquakes have killed and injured more than 800000 people. In addition to physical injuries, evidence has shown that many earthquake victims suffered from mental disorders, which in turn, caused physical diseases and reduced their quality of life $[3,4]$.

According to Rivera, "Numerous studies have attempted to identify psychological resources that positively help prevent or reduce the risk of mental disorders". Among the known protective variables are self-efficacy and spirituality [5]. One of the essential factors in maintaining physical and mental health status is to improve selfefficacy status [6]. Alfred Bandura coined the concept of self-efficacy, and it is a part of Bandura's social cognitive theory. It means believing in one's ability to complete tasks and achieve goals. It can affect the amount of effort and level of performance [7]. Self-efficacy is a vital prerequisite for behavior because it acts as an independent part of the basic skills of the individual, and most of those who are confident about their ability to take care of themselves have more tendency to complete their tasks [8].

People with a higher level of self-efficacy set higher goals for themselves, and as a result, their behavior becomes more desirable, while for people with lower self-efficacy, the result of their behavior is not appropriate. People with low self-efficacy can easily be persuaded that their behavior is useless, and therefore, they give up quickly. On the other hand, people with a high level of self-efficacy overcome obstacles and problems by improving self-management skills and perseverance. They have more control over their affairs and experience less uncertainty $[9,10]$.

On the other hand, human beings may take refuge in God in difficult life situations, where they have lost their support and hope, and it usually has a positive effect on their performance [11]. Many people resort to spirituality in the face of diseases and problems. Besides, there is evi- dence that resorting to spirituality is effective in dealing with and improving mental and physical problems [12].

Spirituality refers to how people seek and express the meaning and purpose of their lives and experiences in connection with themselves, others, nature, spirituality, or sanctification. Among these, spiritual coping means using religion and spirituality to deal with stressful situations that occur during life $[13,14]$. Spiritual coping resulting from a sense of connection with God reduces the effects of stressful life situations and has a positive effect on improving mental state and satisfaction. In general, spirituality and spiritual coping is an integral part of an individual's lives and has significant effects on their health [15].

Hope, like spirituality and spiritual coping, is another concept that plays a vital role in dealing with problems and tensions resulting from it $[11,16,17]$. Life expectancy is a statistical indicator that shows the average life expectancy in society. In other words, each member of that community can expect to live for several years. As health and therapeutic indicators improve, life expectancy will increase. Furthermore, this index is one of the indicators for measuring the progress and backwardness of countries [18]. Life expectancy is an essential criterion for the impact of mortality on life expectancy and reflects a disease in a population [19].

Nurses, especially community health nurses, have a set of skills to serve the community, and they are serving for more than a century in the field of disasters. Traumatic events, such as earthquakes, are hazardous and beyond the ordinary experiences of individuals. Many people have specific psychological reactions to traumatic events. They startle and get confused at first and do not realize what harm has been done to them, but then thoughts, feelings, or behaviors appear among people who have been hurt or have witnessed painful scenes. These people get worried about being alone, their safety, health, and the lives of their loved ones, and they will experience bewilderment. Given that few studies have been conducted on problems and disorders in earthquake-stricken victims living in Sarpol-e Zahab, the present study aimed to determine the relationship between self-efficacy, spiritual coping, and life expectancy in earthquake-stricken adults living in Sarpol-e Zahab City, Iran, in 2019.

\section{Materials and Methods}

The present study is a descriptive-analytical cross-sectional study conducted on adults affected by the earthquake in Sarpol-e Zahab City of Kermanshah Province, 
Iran, in 2019. The statistical population included all adult residents (20 or more years old) affected by the earthquake in Sarpol-e Zahab City. Sampling performed using the convenience sampling method.

Moreover, the sample size required was calculated by determining the simple correlation coefficient between self-efficacy with spiritual coping and life expectancy at the level of error $\alpha=0.05$, test power of $80 \%(\beta=0.2)$ and the minimum value of correlation coefficient for the significance of the relationship of 0.25 in the hypothesis test $\rho=0$ against $\rho=r \neq 0$. By considering the sample exclusions and their reluctance to participate at any time of the study period, the number of samples estimated to be 123 that entered the study based on the inclusion criteria, i.e., all adults affected by the earthquake in Sarpol-e Zahab who were willing to cooperate and were resident of Sarpol-e Zahab City during the earthquake.

In the present study, data collection was performed using a questionnaire consisting of four sections. The first part included demographic information of the subjects, such as age, gender, financial status, marital status, education, occupation, housing status, number of family members, number of children, monthly income, the rate of property damaged, and losing someone in the earthquake. The second part included Sherer standard General Self-efficacy (GSE) scale (Appendix 1). This questionnaire has 17 questions that are scored on a Likert-type scale from "strongly disagree" (score 1) to "strongly agree" (score 5). Items 1, 3, 8, 9, 13, 15 are scored from 1 to 5 , and the rest from 5 to 1 in reverse order. The maximum score was 85, and the minimum 17 .

Higher scores indicated a high sense of self-efficacy, and the lower scores weak self-efficacy. This scale has been translated and validated by Barati (1996). Bakhtiari Barati (1997) examined the correlation of this scale with measures of several personality traits (Rotter's locus of control scale, personal control subscale, the MarloweCrowne social desirability scale, and the Rosenberg interpersonal competency scale) to measure the construct validity of the general self-efficacy scale. The predicted correlation between the self-efficacy scale and personality traits measurements was average ( 0.61 at the significance level of 0.05) and confirmed the target construct. Also, the reliability coefficient of the scale using the Guttman split-half scaling method was 0.76 . This value was obtained using the Cronbach alpha coefficient of 0.79 [20].

The third part of the questionnaire was the Herth Hope Index (Appendix 2) developed in 1999 to measure life expectancy and had 12 three-choice questions. Items of the questionnaire had options of "I agree", "I am not sure", and "I disagree". There was no time limit for completing the questionnaire. For questions 3 and 6, options "I agree", "I am not sure", and "I disagree" were assigned scores of 1, 2, and 3, respectively. The rest of the questions are scored in reverse. A score of 12-24 showed a low level of hope; scores 25-30 showed an average level of hope and scores 31-36 showed a high level of hope.

The fourth part of the standard questionnaire was spiritual coping. This questionnaire was a self-report tool to measure the individual's spiritual coping. The questionnaire was designed and validated by Rassouli et al. (2009) using both qualitative and quantitative methods according to the religious and cultural context of Iran. This questionnaire consisted of 39 questions and investigated three components (the meaning of life, communication with God, seeking spiritual support). The scoring method for all items was as follows: 5: Strongly agree; 4: Agree; 3: Not sure; 2: Disagree; 1: Strongly disagree. Questions 1 to 15 investigated the meaning of life, questions 16 to 26 investigated communication with God; finally, the remaining questions investigated seeking spiritual support.

In their study, Rassouli et al. (2009) reported the validity of the spiritual coping scale (Appendix 1) to be $0.897 \mathrm{ob}$ tained by correlating it with the adolescents' spiritual attitude scale. Moreover, the test-retest correlation coefficient with three weeks interval was reported to be 0.712 . Also, the reliability of their questionnaire was reported to be 0.96, using the Cronbach alpha [15]. After obtaining their satisfaction and explaining the objectives of the study, the researcher gave the questionnaire to the subjects. After collecting information using the questionnaires completed, SPSS v. 24 was used for statistical analysis. To analyze the obtained data, descriptive statistical tests such as mean and standard deviation, frequency, frequency percentage, and inferential tests such as the Spearman correlation, independent $t$ test, and Analysis of Variance (ANOVA) were used.

\section{Results}

Among 135 subjects of the study, 65.2\% were men, and $34.8 \%$ were women. In terms of age, the highest frequency was related to individuals in the age group of 20-40 years $(48.9 \%)$, and the Mean $\pm \mathrm{SD}$ age was $41.64 \pm 11.49$ years. About $88.1 \%$ were married, and $43.7 \%$ had 1 or 2 children (Table 1). Self-efficacy for $6.7 \%$ of people was at a poor level, for $64.4 \%$ at a moderate level, and for $28.9 \%$ at a good level. The mean self-efficacy score for the subjects was $55.64 \pm 10.29$ (Table 2). The spiritual coping score was at an appropriate level for $70.4 \%$, 
Table 1. Frequency distribution of subjects based on individual characteristics

\begin{tabular}{|c|c|c|c|}
\hline Variable & Category & No. (\%) & Mean \pm SD \\
\hline \multirow{2}{*}{ Gender } & Male & $88(65.2)$ & \multirow{2}{*}{ - } \\
\hline & Female & $47(34.8)$ & \\
\hline \multirow{3}{*}{ Age (y) } & $20-40$ & $66(48.9)$ & \multirow{3}{*}{$61.64 \pm 11.49$} \\
\hline & $41-60$ & $65(48.1)$ & \\
\hline & Over 60 & $4(3.0)$ & \\
\hline \multirow{2}{*}{ Marital status } & Married & $119(88.1)$ & \multirow{2}{*}{ - } \\
\hline & Single & $16(11.9)$ & \\
\hline \multirow{5}{*}{ Number of children } & Single (no children) & 16 (11.9) & \multirow{5}{*}{$2.54 \pm 1.73$} \\
\hline & No children & $8(5.9)$ & \\
\hline & 1-2 children & $59(43.7)$ & \\
\hline & 3-4 children & $42(31.1)$ & \\
\hline & 5 children and more & $10(7.4)$ & \\
\hline Total & & $135(100.0)$ & \\
\hline
\end{tabular}

Table 2. Frequency distribution of subjects based on self-efficacy level and average self-efficacy score

\begin{tabular}{lcccc}
\hline & Category & No. (\%) & Mean \pm SD \\
\hline Level of self-efficacy & Weak (scores 17-39) & $9(6.7)$ & \\
& & Moderate (scores 40-62) & $87(64.4)$ & $55.64 \pm 10.29$ \\
& & Good (scores 63-85) & $39(28.9)$ \\
& Total & & $135(100.0)$ \\
\hline & & |llealth in \\
Emergencies and [D]isasters [Oluarterly
\end{tabular}

$63.7 \%$, and $63.0 \%$ in the meaning of life, communication with God, and seeking spiritual support, respectively.

The average scores of the subjects were $59.46 \pm 13.54$, $41.70 \pm 10.33,49.31 \pm 12.27$ for the meaning of life, communication with God, and seeking spiritual support, respectively. In general, the spiritual coping scores were low, moderate, and high for $8.9 \%, 23.7 \%$, and $67.4 \%$ of the subjects, respectively. The Mean \pm SD score of spiritual coping for the subjects was $150.47 \pm 35.17$ (Table 3). Life expectancy scores were low, moderate, and high for $25.9 \%, 28.1 \%$, and $45.9 \%$ of the subjects, respectively. The Mean \pm SD life expectancy score for the subjects was $28.44 \pm 5.75$ (Table 4). The results of the Pearson correlation coefficient showed a direct and significant relationship between self-efficacy and spiritual coping ( $\mathrm{r}=0.274$, $\mathrm{P}=0.001)$ and dimensions of meaning of life $(\mathrm{r}=0.311$, $\mathrm{P}<0.001)$, communication with $\operatorname{God}(\mathrm{r}=0.220, \mathrm{P}=0.010)$, and seeking spiritual support $(\mathrm{r}=0.258, \mathrm{P}=0.003)$.
With the increasing self-efficacy of individuals, the level of spiritual coping in them has also increased significantly, and vice versa. According to the result of the Pearson correlation coefficient, there was a direct and significant relationship between self-efficacy and life expectancy scores $(r=0.511, \mathrm{P}<0.001)$ among Sarpol-e Zahab earthquake victims. As the self-efficacy of individuals increased, their life expectancy increased significantly and vice versa. In addition, according to the result of the Pearson correlation coefficients, there was a direct and significant relationship between life expectancy and spiritual coping scores $(\mathrm{r}=0.592, \mathrm{P}<0.001)$, the meaning of life $(\mathrm{r}=0.584, \mathrm{P}<0.001)$, communication with God ( $\mathrm{r}=0.542, \mathrm{P}=0.010)$, and seeking spiritual support $(\mathrm{r}=0.595, \mathrm{P}<0.001)$. As the life expectancy of subjects increased, the level of spiritual coping also increased significantly among them (Table 5). 
Table 3. Frequency distribution of subjects based on spirituality coping level and the average spirituality coping score

\begin{tabular}{|c|c|c|c|}
\hline Variable & Category & No. (\%) & Mean $\pm S D$ \\
\hline \multirow{3}{*}{ Meaning of life } & Weak (scores 15-35) & $11(8.1)$ & \\
\hline & Moderate (scores 36-55) & $29(21.5)$ & $59.46 \pm 13.54$ \\
\hline & Good (scores 56-75) & $95(70.4)$ & \\
\hline \multirow{3}{*}{ Communication with God } & Weak (scores 11-25) & $14(10.4)$ & \\
\hline & Moderate (scores 26-40) & 35 (25.9) & $41.70 \pm 10.33$ \\
\hline & Good (scores 41-55) & $86(63.7)$ & \\
\hline \multirow{6}{*}{ Seeking spiritual support } & Weak (scores 13-30) & $15(11.1)$ & \\
\hline & Moderate (scores 31-48) & 35 (25.9) & $49.31 \pm 12.27$ \\
\hline & Good (scores 49-65) & $85(63.0)$ & \\
\hline & Weak (scores 39-91) & $12(8.9)$ & \\
\hline & Moderate (scores 92-143) & $32(23.7)$ & $150.47 \pm 35.17$ \\
\hline & Good (scores 144-195) & $91(67.4)$ & \\
\hline \multicolumn{2}{|c|}{ Total } & 135 (100.0) & \\
\hline
\end{tabular}

Table 4. Frequency distribution of subjects based on life expectancy level and average life expectancy score

\begin{tabular}{lcccc}
\hline & Category & No. (\%) & Mean \pm SD \\
\hline Level of life expectancy & Weak (scores 12-24) & $35(25.9)$ & $38(28.1)$ & $28.44 \pm 5.75$ \\
& & Moderate (scores 25-30) & $62(45.9)$ \\
\hline & Tood (scores 31-36) & & $135(100.0)$ \\
\hline
\end{tabular}

Table 5. Investigating the relationship between self-efficacy, spiritual coping, life expectancy, and their dimensions

\begin{tabular}{cccc}
\hline Variable & \multicolumn{3}{c}{ Self-efficacy } \\
\cline { 2 - 4 } & No. & Correlation Coefficient & P \\
\hline Meaning of life & 135 & $0.311^{* *}$ & $<0.001$ \\
\hline Communication with God & 135 & $0.220^{*}$ & 0.010 \\
Seeking spiritual support & 135 & $0.258^{* *}$ & 0.003 \\
Spiritual coping & 135 & $0.274^{* *}$ & 0.001 \\
Life expectancy & 135 & $0.511^{* *}$ & $<0.001$ \\
Meaning of life & 135 & $0.584^{* *}$ & $<0.001$ \\
\hline Communication with God & 135 & $0.542^{* *}$ & $<0.001$ \\
\hline Seeking spiritual support & 135 & $0.595^{* *}$ & $<0.001$ \\
Spiritual coping & 135 & $0.592^{* *}$ & $<0.001$ \\
\hline
\end{tabular}




\section{Discussion}

The results of this study showed a significant positive relationship between self-efficacy and spiritual coping and life expectancy. In the present study, the majority of subjects had a moderate and reasonable level of life expectancy and spiritual health and a moderate level of self-efficacy. Mikaeli et al. (2015) conducted a study entitled "Analysis of the relationship between hope, self-efficacy, motivations, and academic stressors and academic adjustment among undergraduate students of Urmia University". The results of their study showed that self-efficacy, motivation, hope, academic stressors, and academic adjustment had a significant relationship with each other [20]. Their findings were consistent with those of our study in terms of the relationship between self-efficacy and hope.

The results of the study by Marzabadi (2015) entitled "The relationship between physical and mental health and spirituality and self-efficacy in military personnel" showed a significant positive relationship between physical, mental health, and self-efficacy and also between spirituality and self-efficacy. In general, the results showed that the self-efficacy of military personnel could be increased by promoting physical and mental health and spirituality [21]. These findings are consistent with those of the present study in terms of the relationship between spirituality and self-efficacy.

Chabok (2017) also investigated the relationship between self-efficacy and spiritual health in the Iranian elderly. The results of his study indicated a significant relationship between self-efficacy and spiritual health and its existential and religious dimensions. Another result of his study showed that increasing spirituality and spiritual health in the elderly could improve selfefficacy and promote mental health [22]. Hassan Shahi (2016) conducted a study entitled "The relationship between spiritual health, self-efficacy, and discouragement in medical students". The result of his study showed a significant inverse relationship between discouragement and self-efficacy, in such a way that the level of self-efficacy decreased with increasing discouragement. On the other hand, there was a significant positive relationship between spiritual health and self-efficacy, and increasing spiritual health led to increased self-efficacy [23]. These findings are consistent with those of the present study regarding the relationships between spiritual health and self-efficacy and hope and self-efficacy.

In explaining the obtained results, it can be said that one of the factors that can reduce pain during illness and even increase the hope and likelihood of recovery is spirituality, and anyone can experience it [24, 25]. Spirituality can be a source of support for the sick and at-risk people [26]. Increasing a person's spiritual level can increase his or her self-esteem, create positive emotions, and promote effective care practices for creating a healthy lifestyle. They all improve the quality of life [27]. On the other hand, self-efficacy means believing in one's ability to complete tasks and achieve one's goals. This concept can affect the amount of effort and level of performance [7]. Therefore, regarding the possible cause of the relationship between self-efficacy and spiritual coping and life expectancy, people who have higher spirituality and consider spirituality as a way to overcome the problems arisen and engage in spiritual coping believe in their abilities more. They have taken refuge in God, and after God in themselves and their abilities to improve the situation, so there is more life expectancy in these people.

\section{Conclusion}

The findings of the present study showed a high level of correlation between self-efficacy, life expectancy, and spiritual coping. People with high spiritual health and life expectancy are more easily cope with their problems, and strengthening spiritual health and life expectancy increases people's adaptation to the circumstances. Also, spiritual health and life expectancy in people develop a new and positive attitude towards themselves, others, and the world around them. Because self-efficacy is people's belief in their abilities and skills, a high level of spiritual health and life expectancy in people make them have a favorable view of themselves and judge their skills and abilities correctly. Thus, a high level of spiritual health and life expectancy will lead to a high level of self-efficacy. Therefore, it is recommended that training programs be designed to increase self-efficacy, life expectancy, and spiritual coping skills in earthquake victims.

\section{Research limitations}

Lack of random selection of study subjects was one of the limitations of the research.

\section{Ethical Considerations}

\section{Compliance with ethical guidelines}

This study was approved by the Ethics Committee of the Kermanshah University of Medical Sciences (Code: IR.IAU.YAZD.REC.1398.008). Also, Informed consent was obtained from all the research participants. The 
present study did not cause any harm or cost to the participants.

\section{Funding}

The paper was extracted from the Master's thesis of the first author, Department of Community Health Nursing, Community Health Research Center, Faculty of Nursing and Midwifery, Khorasgan Branch, Islamic Azad University.

\section{Authors' contributions}

All authors contributed equally in preparing all parts of the research.

\section{Conflict of interest}

The authors declared no conflict of interest.

\section{Acknowledgments}

Researchers express their gratitude and appreciation to the esteemed officials of the Islamic Azad University, Isfahan Branch (Khorasgan), and the study participants.

\section{References}

[1] Soltani Nejad A, Barshan A, Baniasad A, Soltani Nejad A, Sam A, Sadie A. Investigating Social Vulnerability of the Elderly in the Earthquakes of Bam, Varzaghan, and Ahar. Iran J Ageing. 2017; 12(3):360-71. [DOI:10.21859/sija.12.3.360]

[2] Ardalan A, Babaie J, Shaterzadeh A, Ronaghi M, Mehdizadeh $\mathrm{K}$, Hamidirad $\mathrm{H}$, et al. [Public health system response to 5 December 2012 South Khorasan earthquake (a case study) (Persian)]. Journal Of Rescue \& Relief. 2014; 6(2):15-22. http://jorar.ir/browse.php?a_id=184\&sid=1\&slc_lang=fa

[3] MacKenzie JS, Banskota B, Sirisreetreerux N, Shafiq B, Hasenboehler EA. A review of the epidemiology and treatment of orthopaedic injuries after earthquakes in developing countries. World J Emerg Surg. 2017; 12(1):9. [DOI:10.1186/ s13017-017-0115-8] [PMID] [PMCID]

[4] Ren J-H, Chiang C-LV, Jiang X-L, Luo B-R, Liu X-H, Pang M-C. Mental disorders of pregnant and postpartum women after earthquakes: A systematic review. Disaster Med Public Health Prep. 2014; 8(4):315-25. [DOI:10.1017/dmp.2014.62] [PMID]

[5] González-Rivera J, Rosario-Rodríguez A. Spirituality and self-efficacy in caregivers of patients with neurodegenerative disorders: An overview of spiritual coping styles. Religions. 2018; 9(9):276. [DOI:10.3390/rel9090276]

[6] Salamizadeh A, Mirzaei T, Ravari A. The impact of spiritual care education on the self-efficacy of the family caregivers of elderly people with Alzheimer's disease. Int J Community Based Nurs Midwifery. 2017; 5(3):231-8. [PMID] [PMCID]
[7] Didarloo A, Rahmatnezhad L, Sheikhi S, Khodai F. Relationship of spiritual health and perceived stress with breastfeeding self-efficacy: A survey on mothers with hospitalized neonates. Int J Pediatr. 2017; 5(12):6179-88. [DOI:10.22038/ IJP.2017.25961.2210]

[8] Aghamohammadi T, Maddah SSB, Mohammadi Shahbolaghi F, Dalvandi A, Khaleghipour M. [The impact of selfmanagement program on selfefficacy of elderly patients with heart failure (Persian)]. J Urmia Nurs Midwifery Fac. 2017 14(12):1013-23. http://unmf.umsu.ac.ir/article-1-2938-en. html

[9] Hossiennezhad M, Azizzadeh Forozi M, Mohammad-Alizadhe S, Haghdoust A. [Role of self efficacy predictors in nutritional behaviors of Kerman high school female students in 2006-2007 academic year (Persian)]. J Shahid Sadoughi Univ Med Sci Health Serv. 2008; 16(3):49-56. http://jssu.ssu.ac.ir/ article-1-579-en.html

[10] Musavimoghadam SR, Karamian M, Usefis S. The relationship between spiritual health, ethical intelligence, organizational identity formation and self-efficacy (case study refinery of Ilam). Int J Trop Med. 2016; 11(1):9-12. [DOI:10.36478/ ijtmed.2016.9.12

[11] Charzyńska E. Sex differences in spiritual coping, forgiveness, and gratitude before and after a basic alcohol addiction treatment program. J Relig Health. 2015; 54(5):1931-49. [DOI:10.1007/s10943-015-0002-0] [PMID] [PMCID]

[12] Ironson G, Kremer H, Lucette A. Relationship between spiritual coping and survival in patients with HIV. J Gen Intern Med. 2016; 31(9):1068-76. [DOI:10.1007/s11606-0163668-4] [PMID] [PMCID]

[13] Asgari P. [The effectiveness of spiritual therapy on quality of life and adjustability in the elderly, with an emphasis on the teachings of islam (Persian)]. J Aging Psychol. 2017 2(4):281-91. https://www.sid.ir/en/journal/ViewPaper. aspx?id=573506

[14] Matos TDdS, Meneguin S, Ferreira MdLdS, Miot HA Quality of life and religious-spiritual coping in palliative cancer care patients. Rev Lat Am Enfermagem. 2017; 25:e2910 [DOI:10.1590/1518-8345.1857.2910] [PMID] [PMCID]

[15] Marashian F, Esmaili E. [The relationship between spiritual coping and life satisfaction with mental health among the students of islamic azad university of Ahvaz (Persian)]. J Soc Psychol (New Findings In Psychology). 2012; 7(24):85-98 https:/ / www.sid.ir/fa/journal/ViewPaper.aspx?id=203017

[16] Dehbashi F, Sabzevari S, Tirgari B. [The relationship between spiritual well-being and hope in Hemodialysis patients referring to the Khatam Anbiya hospital in Zahedan 2013-2014 (Persian)]. Med Ethics J. 2015; 8(30):77-96. https:// www.sid.ir/en/journal/ViewPaper.aspx?id=410946

[17] Ghanbari Afra L, Zaheri A. [Relationship of anxiety, stress, and depression with spiritual health in patients with acute coronary artery disease (Persian)]. J Educ Community Health. 2017; 4(2):28-34. [DOI:10.21859/jech.4.2.28]

[18] Hajiazizi AH, Bahmani B, Mahdi N, Manzari Tavakol $\mathrm{V}$, Barshan A. [Effectiveness of group logotherapy on death anxiety and life expectancy of the elderly living in boarding houses in Kerman (Persian)]. Iran J Ageing. 2017; 12(2):22031. [DOI:10.21859/sija-1202220] 
[19] Salimi T, Tavangar H, Shokripour S, Ashrafi H. [The effect of spiritual self-care group therapy on life expectancy in patients with Coronary Artery Disease: An educational trial (Persian)]. J Rafsanjan Univ Med Sci Health Serv. 2016; 15(10):917-28. http://journal.rums.ac.ir/article-1-3337-en.html

[20] Michael F, Fathi G, Shohoodi M, Zandi K. [Analysis of the relationship between hope, self-efficacy, motivation, and stress with academic adaptation among graduate students of Urmia University (Persian)]. New Thought Educ. 2015; 11(1):57-78. [DOI:10.22051/JONTOE.2015.390]

[21] Azad Marzabadi E, Fathi-Ashtiani A, Ahmadi-Zade MJ, Anisi J, Zamani-Nasab R. [Relationship between physicalmental health and spirituality with self efficacy in military staff (Persian)]. Journal Mil Med. 2015; 16(4):217-23. http:// militarymedj.ir/article-1-1336-fa.html

[22] Chabok M, Kashaninia Z, Haghani H. The relationship between spiritual health and general self-efficacy in the iranian elderly. J Client-Cent Nurs Care. 2017; 3(2):125-32. [DOI:10.32598/jccnc.3.2.125]

[23] Hasanshahi M, Mazaheri MA, Baghbanian A. Relationship between spiritual health, hopelessness, and self-efficacy in medical sciences students. Iran J Psychiatr Behav Sci. 2018; 12(2):e2071. [DOI:10.5812/ijpbs.2071]

[24] Cozier YC, Yu J, Wise LA, VanderWeele TJ, Balboni TA, Argentieri MA, et al. Religious and spiritual coping and risk of incident hypertension in the black women's health study. Ann Behav Med. 2018; 52(12):989-98. [DOI:10.1093/abm/ kay001] [PMID] [PMCID]

[25] Dhama K, Gupta R, Singla A, Patthi B, Ali I, Niraj LK, et al. An insight into spiritual health and coping tactics among dental students; a gain or blight: A cross-sectional study. J Clin Diagn Res. 2017; 11(8):ZC33. [DOI:10.7860/ JCDR/2017/25358.10371] [PMID] [PMCID]

[26] Neves Nunes SA, Fernandes HM, Fisher JW, Fernandes MG. Psychometric properties of the Brazilian version of the lived experience component of the Spiritual Health And LifeOrientation Measure (SHALOM). Psicol Reflex Crit. 2018; 31(1):2. [DOI:10.1186/s41155-018-0083-2] [PMID] [PMCID]

[27] Abu HO, Ulbricht C, Ding E, Allison JJ, Salmoirago-Blotcher E, Goldberg RJ, et al. Association of religiosity and spirituality with quality of life in patients with cardiovascular disease: A systematic review. Qual Life Res. 2018; 27(11):2777-97. [DOI:10.1007/s11136-018-1906-4] [PMID] [PMCID] 


\section{Appendix}

Appendix 1. Sherer General Self-Efficacy Scale (GES)

\begin{tabular}{|c|c|c|c|c|c|c|}
\hline Row & Phrases & 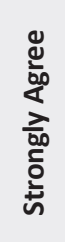 & 迹 & 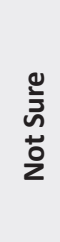 & 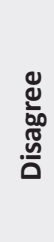 & 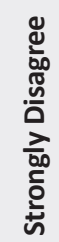 \\
\hline
\end{tabular}

1

When I make plans, I am certain I can make them work

2

One of my problems is that I cannot get down to work when I should

If I cannot do a job the first time, I keep trying until I can

4

When I set important goals for myself, I rarely achieve them

I give up on things before completing them

I avoid facing difficulties

7

If something looks too complicated, I will not even bother to try it

8

When I have something unpleasant to do, I stick to it until I finish it

9

When I decide to do something new, I go right to work on it 
Appendix 2. The Herth Hope Index

1. I have a positive look on life
a. I agree
b. I am not sure
c. I disagree

2. I have a goal for today, tomorrow, and the next days
a. I agree
b. I am not sure
c. I disagree

3. I feel everybody is alone
a. I agree
b. I am not sure
c. I disagree

4. I can see the light of hope
a. I agree
b. I am not sure
c. I disagree

5. I have faith, and that faith makes me calm
a. I agree
b. I am not sure
c. I disagree

6. I feel scared about the future
a. I agree
b. I am not sure
c. I disagree

7. I can remember happy and pleasant times
a. I agree
b. I am not sure
c. I disagree

8. I have deep power, and I rely on myself
a. I agree
b. I am not sure
c. I disagree

9. I can understand love and affection, and also I can love others
a. I agree
b. I am not sure
c. I disagree

10. I feel I have control over my life
a. I agree
b. I am not sure
c. I disagree

11. I believe that everybody is not the same as yesterday, and every day has its characteristics
a. I agree
b. I am not sure
c. I disagree

12. I feel that my life is valuable, both materially and spiritually
a. I agree
b. I am not sure
c. I disagree 
Appendix 3. Spiritual Coping Scale (Rassouli et al., 2009)

\begin{tabular}{|c|c|c|c|c|c|c|}
\hline Row & Phrases & 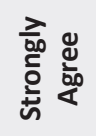 & $\frac{\searrow}{\frac{\bigcup}{60}}$ & $\begin{array}{l}\frac{0}{5} \\
\text { जั } \\
\stackrel{0}{z}\end{array}$ & 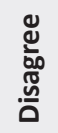 & 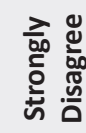 \\
\hline 1 & God is my supporter & & & & & \\
\hline 2 & God has guided me & & & & & \\
\hline 3 & I thank God that I have a place to live & & & & & \\
\hline 4 & I seek help from God & & & & & \\
\hline 5 & God has helped me a lot in life & & & & & \\
\hline 6 & Life difficulties are tests by God & & & & & \\
\hline 7 & I trust in God in times of trouble & & & & & \\
\hline 8 & Faith in God makes me think that someone is always helping me & & & & & \\
\hline 9 & God is my best friend & & & & & \\
\hline 10 & God has solved many of my unsolvable problems & & & & & \\
\hline 11 & When I communicate with God, the problems do not seem so big & & & & & \\
\hline 12 & If it were not for God's grace, my life situation would have been worse & & & & & \\
\hline 13 & Gratitude for God's blessings is one of the ways to communicate with Him & & & & & \\
\hline 14 & I seek help from God to deal with my current problems & & & & & \\
\hline 15 & Belief in God solves problems & & & & & \\
\hline 16 & Praying is one of the ways to deal with the problem & & & & & \\
\hline 17 & I pray that God will show me the right path and the meaning of life & & & & & \\
\hline 18 & Trusting God makes affairs progress better & & & & & \\
\hline 19 & I pray for the problems of others & & & & & \\
\hline 20 & Trusting God is one way to deal with problems & & & & & \\
\hline 21 & Praying is one way to deal with a problem & & & & & \\
\hline 22 & Thinking about God is one way to communicate with God & & & & & \\
\hline 23 & I like to use spirituality to solve my problems & & & & & \\
\hline 24 & Spirituality solves problems & & & & & \\
\hline 25 & Because of the current situation, I consider myself close to God & & & & & \\
\hline 26 & Spirituality has played a significant role in my life & & & & & \\
\hline 27 & Spirituality makes peace & & & & & \\
\hline 28 & I feel that God cares about me & & & & & \\
\hline 29 & I seek spiritual help to achieve peace & & & & & \\
\hline 30 & Talking about spiritual matters calms me down & & & & & \\
\hline 31 & God helps me with prayer & & & & & \\
\hline 32 & Talking about spiritual issues solves the problems & & & & & \\
\hline 33 & I have received many Divine aids & & & & & \\
\hline 34 & God listens when I talk to Him & & & & & \\
\hline 35 & Working is a spiritual solution & & & & & \\
\hline 36 & If God deems it expedient, my problem will be solved & & & & & \\
\hline 37 & Strong faith in God reduces problems & & & & & \\
\hline 38 & Art is a kind of spirituality & & & & & \\
\hline 39 & Spiritual people are confident individuals & & & & & \\
\hline
\end{tabular}


This Page Intentionally Left Blank 